Catrin Norrby

\title{
Interaction and Variation in Pluricentric Languages - communicative patterns in Sweden Swedish and Finland Swedish
}

\section{Introduction}

Interaction and Variation in Pluricentric Languages (IVIP) is a research programme which was funded for eight years (2013-2020) by the Swedish research foundation Riksbankens Jubileumsfond for the Advancement of the Humanities and Social Sciences. ${ }^{1}$ The overall purpose of the Riksbanken programme grant scheme is to provide funding for "joint, well-integrated research assignments in the social sciences and humanities carried out over relatively long periods by groups of merited researchers connected with Sweden". ${ }^{2}$ While there is a requirement for active involvement of Swedish-based researchers, or a Swedish research institution, the participation of researchers from other countries is also encouraged. The IVIP programme was a binational collaboration between researchers in Sweden and Finland. It was led and administered from Stockholm University with Catrin Norrby as the researcher in charge of the overall programme. The other senior participants were Jenny Nilsson at the Institute of Language and Folklore in Gothenburg, Jan Lindström at Helsinki University and Camilla Wide at Turku University. Together these four researchers formed the programme executive.

The main purpose of this report is to give an overview of the research programme's objectives and overall design, its theoretical and methodological approach, and empirical data. The programme findings have, to date, resulted in some sixty publications; for details the reader is directed to the list of publications available at the IVIP homepage. ${ }^{3}$

1 Grant ID: M12-0137:1.

2 https://www.rj.se/en/research--funding/support-forms/RJ-programmes/; last access on 21 May 2021.

3 https://www.su.se/svefler/ivip/publikationer-publications/publications-ivip-1.123078; last access on 21 May 2021.

Catrin Norrby, Department of Swedish Language and Multilingualism, Stockholm University, 10691 Stockholm, Sweden, catrin.norrby@su.se 


\section{Background to IVIP and overall programme objectives}

To state the rather obvious, every project emanates from an idea, which forms the incentive for the further conceptualisation and development of a research proposal. Ideas do not however come about in a vacuum but are intrinsically connected to their historical and socio-political context. The plan to investigate pluricentricity based on interactions in the national varieties of Swedish evolved partly from an earlier Australian research project on address practices in the pluricentric languages English, French, German and Swedish (Clyne/Norrby/Warren 2009), which had uncovered some interesting pragmatic differences between national varieties of these languages, and partly from the realisation that there was very little research on pluricentricity from an interactional perspective at the time. This was evidenced, for instance, at the first International Conference on Pluricentric Languages held in Braga, Portugal in 2010 (Soares da Silva/Torres/Gonçalves 2011) as well as the inaugural meeting of the international network for research on non-dominant varieties in Graz 2011 (Muhr 2012). Accordingly, the main motivation of the research programme was to address this research gap and, more specifically, to contribute to the fuller description of variation in communicative patterns between the two national varieties of Swedish based on comparable datasets.

In Sweden, Swedish is the majority language, spoken by an estimated $85 \%{ }^{4}$ of the population as an L1 whereas Finland Swedish is spoken by a numerical minority of 5.2\% in Finland. Nevertheless, Finland Swedish enjoys a strong legal position in Finland, equal to Finnish and regulated through the Language Act (Finlex 2003). The relationship between the two national varieties of Swedish is asymmetrical, with Sweden Swedish as the dominant, and Finland Swedish as the non-dominant variety (see Norrby et al. 2020 and references therein). Finland Swedish has been comprehensively documented with regard to phonological, lexical and other structural properties (e.g. Hällström-Reijonen/Reuter 2008; Wide/Lyngfelt 2009) to an extent unusual for a non-dominant variety, but no systematic comparison existed for pragmatic and interactional features of the national varieties of Swedish at the time. This provided the impetus for an investigation based on equivalent datasets from Sweden and Finland in order to fill this research gap.

The aims of the research programme were threefold. Its empirical aim was to further our knowledge of pragmatic and interactional patterns in Sweden Swedish and Finland Swedish, based on interactional data from three public domains in each country: service, education and health care. Its theoretical aim was to contribute to the international development of research in the field of pluricentricity. By combining

4 Sweden does not collect statistical data on language, so any numerical information is an estimate based on a variety of sources (see Parkvall 2017). 
the theoretical and methodological approaches of conversation analysis (e.g. Sacks/ Schegloff/Jefferson 1974) and variational pragmatics (Schneider/Barron 2008) the programme aimed to shed light on how phenomena at the micro level of actual interactions are interconnected with normative orientations at the macro level of society. Ultimately, the objective of the programme was to increase our understanding of the complex relationships that exist between languages, cultures and nations in pluricentric situations. Finally, there was also a practical aim which was to provide a largescale annotated corpus of interactional data for wider use in the research community.

\section{Theoretical and methodological considerations}

One of our main empirical concerns was to discover the social actions participants typically engage in during a certain activity (e.g. in a service encounter), and how these are accomplished in situ in interaction through verbal and embodied means. From the perspective of pluricentricity, we were particularly interested in comparing the routine ways that interactants perform a certain action (e.g. greetings, requests or assessments) in the Finland-Swedish and Sweden-Swedish interactions. Conversation analysis (CA), with its origins in sociology, and its more language-oriented branch of interactional linguistics (Couper-Kuhlen/Selting 2018), provided a suitable methodological framework for our purposes. Through a detailed sequential analysis, typical of CA, we analysed how various actions were initiated and responded to, and how they were formatted through linguistic and/or non-verbal means.

Both CA and interactional linguistics require a detailed micro-analysis of interactional behaviour where the guiding analytical principle is to adopt a participant perspective as far as possible. This requires repeated scrutiny of the data (original recordings as well as transcripts) and analytical adjustment in light of new discoveries. In this sense, CA produces cumulative evidence of interactional patterns and routines over time. IVIP collected empirical data in three public domains (see below for details on data), which facilitated comparisons of interactional behaviour (routines or practices for expressing a certain social action) across domains and activities within them.

We combined the detailed analytical perspective of CA/interactional linguistics with insights from variational pragmatics, a research framework concerned with intralingual variation in conventions of language use across varieties of a language. In particular, it investigates how such variation, manifest at the micro level of (inter) action, is associated with social and spatial factors of the macro-social context (Schneider/Barron 2008; Barron, this volume). While CA/interactional linguistics and variational pragmatics share an interest in exploring variation at the micro level of interaction, there are methodological differences in how to proceed. In contrast to the qualitative and inductive methods of $\mathrm{CA} /$ interactional linguistics, variational pragmatics applies a broader range of quantitative and qualitative methods, includ- 
ing, for example, studies of pragmatic phenomena based on comparable corpora and elicitation of pragmatic routines through discourse-completion tasks. As one of our aims was to shed light on how language (in interaction), nation and culture are interrelated, we combined insights from CA with variational pragmatics. This allowed us to study how the local level of interaction displays members' normative orientations and understandings of "how to say or do something in culturally appropriate ways", and to chart the distribution of certain features across activities and national contexts (see e.g. Lindström et al. 2019 on task-completing assessments, Nilsson et al. 2020 on greeting behaviour, and Grahn, this volume, all based on service encounter data; Norrby et al. 2015 and Wide et al. 2019 on address practices in medical consultations). Comparing the expression of communicative actions in the two national varieties of Swedish with comparable data from Finnish also enabled us to discover how a shared language and/or shared culture impact on the routine ways of expressing a certain social action (see e.g. Wide et al. 2019 and Nelson et al. 2019 on supervision meetings; for a comprehensive overview in Swedish, see Norrby et al. 2021).

\section{Overall design of IVIP}

The eight-year programme was organised along five separate, but interconnected projects, each of which was associated with at least one of the research aims. They ran for different periods of time, but also overlapped substantially to allow a meaningful interchange of ideas as well as collaborations across projects (see Figure 1 for a visualisation of the programme). Setting the three empirical projects a year apart from one another allowed the researchers involved to draw on prior experiences of data collection and analytical work from one project before starting the next. The theoretical project was initiated when we had sufficient preliminary results from the empirical projects to enable us to relate the interactional details to the wider socio-cultural context. The corpus project ran for the entire duration of the project and was a close cooperation with Språkbanken Text at the University of Gothenburg which is part of The National Language Bank of Sweden. ${ }^{5}$

The service project, the theoretical project and the corpus project were the joint responsibility of the senior research group representing the four participating institutions. The education and health care projects were designed as post-doctoral research projects, but also included representation from the senior research group. To allow for maximum compatibility in terms of data collection, treatment and analysis, all empirical projects thus had equal representation from both countries. The education project was conducted by post-doctoral researchers Sofie Henricson (Turku University)

5 Språkbanken Text: https://spraakbanken.gu.se; last access on 27 June 2021. The National Language Bank of Sweden: sprakbanken.se; last access on 27 June 2021. 


\section{Theoretical project \\ Health care project}

Education project

Service project

Corpus project

\begin{tabular}{llllllll}
\hline 2013 & 2014 & 2015 & 2016 & 2017 & 2018 & 2019 & 2020
\end{tabular}

Figure 1: Programme timeline

and Marie Nelson (Stockholm University) with Catrin Norrby and Camilla Wide from the same universities as senior consulting members. The health care project was the responsibility of post-doctoral researchers Inga-Lill Grahn (The Institute of Language and Folklore, Gothenburg) and Martina Huhtamäki (Helsinki University) with Jenny Nilsson and Jan Lindström from the same institutions as senior advisory members.

\section{The empirical data}

To investigate whether systematic pragmatic and interactional differences exist between the two national varieties of Swedish, a sizeable database was needed to ensure that any variation found was not caused by some other social variables, such as age or gender, or was merely the result of chance. A large and varied database was also considered essential to minimise the risk that any variation in communicative behaviour might primarily be the result of factors such as the physical environment or social practices typical of a certain activity type. By collecting data from three public domains, and from the same type of activities in a particular domain, the goal was to reduce such risks caused by any idiosyncrasies of the data. For that reason, we also refrained from basing the investigation on data from everyday interactions in private settings as this would not have allowed us enough control over contextual circumstances such as the participant framework, topics or physical locations. Taking the above reservations into account, we collected a total of 1,300 encounters, amounting to close to 100 hours of data, from the service, education and health care domains. The data came from 18 locations, equally distributed across Sweden and Finland, and represented major cities, regional centres and smaller municipalities. The data consisted primarily of video-recorded face-to-face interactions, but also included a subset of telephone calls in the service project. In addition to these naturally occurring interactions (natural in the sense that they would have taken place anyway, irre- 
spective of our research purposes) we also conducted some focus group discussions with groups of students at the respective participating universities. The purpose of the focus groups was to canvass popular ideas and perceptions on pragmatic variation in communicative behaviour between Finland and Sweden, and, in particular, to help us interpret our results in light of community beliefs and norm orientations in the wider (national) society. In that sense our findings, based on micro-level interactional analyses, were supported by comments and remarks made by focus group participants.

\subsection{The service project}

The interactional data recorded for the service project amount to more than 40 hours, equally distributed between Finland and Sweden. Data were collected at venues selling tickets to theatre performances, music and sports events, as well as library information desks. All service interactions were recorded on site by several research assistants. There are always challenges involved in collecting naturally occurring data, not least in public domains. The service venues were sometimes very busy with a steady stream of customers. In order to manage the recordings at each location, two, sometimes three, research assistants worked together during a couple of days. In addition to setting up and managing the recording equipment, and collecting written consent from all participants, they also made ethnographic notes and photographed the physical layout of all sites, including the queueing system and service counter configuration. In Sweden, data were sourced from nine venues in six geographical locations. In Finland, data came from 13 venues in seven locations. Given that Swedish is used by a numerical minority in Finland, and subsequently most service outlets operate in the majority language Finnish, more sites were needed to mobilise enough service encounter data in Swedish from Finland. The actual encounters, however, demonstrate the same typical properties irrespective of where they were recorded. They are brief, goal-oriented interactions between customer and service staff and typically last only for a few minutes. Furthermore, they display a rather uniform and predictable format: they are opened by mutual greetings followed by the customer presenting the reason for the visit (e.g. the purchase of tickets, collection of pre-booked tickets, request for information) which the staff then sets out to deal with, and after the delivery of the requested service the encounter is brought to an end by closing devices such as thanking and farewell formulas.

\subsection{The education project}

For the education project, the post-doctoral researchers in charge collected various types of interactions from universities and similar tertiary institutions in both countries. These consisted primarily of supervision meetings and study counselling 
appointments, but various seminar activities, such as student presentations, were also included. Compared to the service encounter data, the interactions in the education project lasted much longer, often for one and up to two hours. The approach taken was to video all types of learning and associated activities made available by the respective institutions in order to gain as much and as varied data as possible. Subsequently, it was then decided which particular recordings were similar enough to facilitate sound comparisons. So, while much larger amounts of data were originally recorded, in the end 10 hours of data from each nation were subject to in-depth comparative interactional analyses. In particular, supervision meetings have been the focus of several comparative investigations (see e.g. Henricson/Nelson 2017 on giving and receiving advice).

\subsection{The health care project}

The primary data for the health care project consisted of videoed activities from preventive health care, such as physical training with personal trainers or physiotherapists, as well as sessions with a health coach. A total of 30 hours of data were collected by the post-doctoral researchers in charge with the help of research assistants. As was the case for the education project data, these sessions were generally long, often lasting for an hour or more. Naturally, there was a focus on physical activities in the sessions, which were characterised by a combination of verbal and embodied action where, for example, a personal trainer or physiotherapist instructs a customer or patient on how to carry out certain exercises, or offers general advice. In the preventive health care project, the form and functions of instructions in training and physiotherapy sessions were compared across the national varieties (see e.g. Lindström et al. 2020). The physical nature of the recorded activities often entailed mobility, and thus required careful consideration as to where to place the camera(s).

In addition to the data above, we had access to two pre-existing corpora of medical consultations, originally collected for two doctoral projects, one in Sweden (Melander Marttala 1995) and the other in Finland (Lindholm 2003). These videoed interactions between doctor and patients were available to us from the start of the programme, and allowed us to conduct some initial comparative studies, particularly focusing on pragmatic variation in address behaviour between the Sweden-Swedish and FinlandSwedish consultations (see e.g. Norrby et al. 2015).

The interactional data from all three empirical projects were transcribed in CLAN, based on a broad version of the verbal transcription conventions developed by Gail Jefferson, and widely used in CA studies (see e.g. Sacks/Schegloff/Jefferson 1974). For publications more detailed transcripts were produced. 


\subsection{The corpus project}

The main objective of the corpus project was to make data from the empirical projects available for future research through the Språkbanken Text corpus tool Korp. ${ }^{6}$ The IVIP corpus will be one of its protected corpora and require a password for access. At the time of writing (June 2021) the IVIP corpus is still under development, but when fully implemented, data from all three domains will be available, albeit with different levels of access, which reflect the relative sensitivity of the data. The service corpus will include both video and audio files as well as transcripts, for the education data audio files and transcripts will be available, while the health care data will be limited to transcripts. Ethical considerations thus guided our decision on what types of data to include. All personal details (such as names, telephone numbers or addresses) have been removed to protect the anonymity of participants.

\section{Final remarks}

In conclusion, a few final remarks on the overall outcome of the research programme will be put forward in order to demonstrate how the results of the detailed interactional analyses may be interpreted in light of predominant socio-cultural tendencies in society. As pointed out above, the theoretical aim of the programme was to offer empirically based insights into the complex relationships that exist between language, culture and nation. Our comparative approach allowed us to document communicative behaviour across the two nations as well as across activity types in fully compatible datasets. As could be expected there were many similarities, but also consistent differences in the ways participants accomplished routine tasks such as requesting goods and services, giving instructions or offering advice, to name a few central social actions prevalent in our data. Overall, the results suggest that there is greater emphasis on building or maintaining interpersonal relationships in the Sweden-Swedish data, whereas the interactions from Finland are more results-oriented and tend to focus on the issues at hand. The participants from Sweden generally favour informal expressions, observable in, for example, informal greeting and address routines, frequent and strongly positive assessments and feedback tokens as ways of displaying interactional engagement and closeness with the interlocutor. In the Finland-Swedish data, the same social actions are expressed, but tend to be phrased in somewhat more formal and restrained ways, with a general tendency towards preserving a certain level of social distance and displaying respect for the integrity of the interlocutor. In turn, these observable national differences reflect the participants' normative orientations to how a certain social action and overall activity, such as taking part in a service trans-

6 https://spraakbanken.gu.se/korp/; last access on 21 May 2021. 
action, a supervision meeting or physical training session, should be conducted. In those studies where we were able to compare with data from Finnish interactions, our Finland-Swedish participants often occupy a middle position, sharing communicative traits both with their Finnish compatriots and their Sweden-Swedish neighbours. Overall, this suggests that Finland Swedes belong to a national cultural community shared by all in Finland, but through language they also orient towards a Swedish-speaking community, a community which is both national, i.e., the Finland-Swedish community, and transnational, including the Sweden-Swedish community. In that sense, Finland Swedish offers particularly fertile ground for the continued inquiry into questions of communication and culture in pluricentric languages.

\section{References}

Clyne, Michael/Norrby, Catrin/Warren, Jane (2009): Language and Human Relations: Address in Contemporary Language. Cambridge: Cambridge University Press.

Couper-Kuhlen, Elizabeth/Selting, Margret (2018): Interactional Linguistics: Studying Language in Social Interaction. Cambridge: Cambridge University Press.

Finlex (2003): Språklag 6. 6. 2003/423. [http://www.finlex.fi/sv/laki/ajantasa/2003/20030423]; last access on 21 May 2021.

Hällström-Reijonen, Charlotta af/Reuter, Mikael (2008): Finlandssvensk ordbok ['Finland-Swedish dictionary']. 4th edition. Helsinki: Schildts.

Henricson, Sofie/Nelson, Marie (2017): Giving and receiving advice in higher education. Comparing Sweden-Swedish and Finland-Swedish supervision meetings. In: Journal of Pragmatics 109, 105-120.

Lindholm, Camilla (2003): Frågor i praktiken. Flerledade frågeturer i läkare-patientsamtal ['Questions in practice. Multi-unit question turns in doctor-patient interaction']. Helsinki: Svenska litteratursällskapet i Finland.

Lindström, Jan/Lindholm, Camilla/Grahn, Inga-Lill/Huhtamäki, Martina (2020): Consecutive clause combinations in instructing activities: Directives and accounts in the context of physical training. In: Maschler, Yael/Pekarek Doehler, Simona/Lindström, Jan/Keevallik, Leelo (eds.): Emergent Syntax for Conversation: Clausal Patterns and the Organization of Action. Amsterdam/Philadelphia: John Benjamins, 245-274.

Lindström, Jan/Norrby, Catrin/Wide, Camilla/Nilsson, Jenny (2019): Task-completing assessments in service encounters. In: Research on Language and Social Interaction, 52, 2, 85-103.

Melander-Marttala, Ulla (1995): Innehåll och perspektiv i samtal mellan läkare och patient. En språklig och samtalsanalytisk undersökning ['Content and perspective in doctor-patient conversations. A linguistic and conversation analytic investigation']. Uppsala: Uppsala University (PhD dissertation).

Muhr, Rudolf (ed.) (2012): Non-Dominant Varieties of Pluricentric Languages: Getting the Picture. Vienna: Peter Lang.

Nelson, Marie/Henricson, Sofie/Savijärvi, Marjo/Mäntynen, Anne (2019): Collaborative actions in supervision meetings. In: Ljung Egeland, Birgitta/Roberts, Tim/Sandlund, Erica/Sundqvist, Pia (eds.): Klassrums-forskning och språk(ande): Rapport från ASLA-symposiet i Karlstad, 12-13 april, 2018. Karlstad: Karlstad University, 235-258. [http://www.diva-portal.org/smash/record. jsf?pid=diva2\%3A1319360\&dswid=3044]; last access on 21 May 2021. 
Nilsson, Jan/Norrby, Catrin/Bohman, Love/Skogmyr Marian, Klara/Wide, Camilla/Lindström, Jan (2020): What is in a greeting? The social meaning of greetings in Sweden-Swedish and FinlandSwedish service encounters. In: Journal of Pragmatics, 168, 1-15.

Norrby, Catrin/Lindström, Jan/Nilsson, Jenny/Wide, Camilla (2020): Pluricentric languages. In: Östman, Jan-Ola/Verschueren, Jef (eds.): Handbook of Pragmatics: 23rd Annual Installment. Amsterdam: John Benjamins, 201-220.

Norrby, Catrin/Lindström, Jan/Nilsson, Jenny/Wide, Camilla (2021): Interaktion och variation $i$ pluricentriska språk. Kommunikativa mönster i sverigesvenska och finlandssvenska. Rapport från ett forskningsprogram ['Interaction and variation in pluricentric languages. Communicative patterns in Sweden Swedish and Finland Swedish. Report from a research programme']. Stockholm: Riksbankens jubileumsfond \& Santérus förlag.

Norrby, Catrin/Wide, Camilla/Lindström, Jan/Nilsson, Jenny (2015): Interpersonal relationships in medical consultations. Comparing Sweden Swedish and Finland Swedish address practices. In: Journal of Pragmatics, 84, 121-138.

Parkvall, Mikael (2017): Sveriges språk i siffror: Vilka språk talas och av hur många? ['Languages spoken in Sweden in numbers. Which languages are spoken and by how many?']. Stockholm: Morfem.

Sacks, Harvey/Schegloff, Emanuel A./Jefferson, Gail (1974): A simplest systematics for the organization of turn-taking for conversation. In: Language 50, 696-735.

Schneider, Klaus P./Barron, Anne (eds.) (2008): Variational Pragmatics: A Focus on Regional Varieties in Pluricentric Languages (Pragmatics and Beyond New Series, 178). Amsterdam/New York: John Benjamins.

Soares da Silva, Augusto/Torres, Amadeu/Gonçalves, Miguel (eds.) (2011): Línguas pluricêntricas: Variação linguística e dimensões sociocognitivas. Pluricentric languages: Linguistic Variation and Sociocognitive Dimensions. Braga: Aletheia, Publicações da Faculdade de Filosofia da Universidade Católica Portuguesa.

Wide, Camilla/Lappalainen, Hanna/Rouhikoski, Anu/Norrby, Catrin/Lindholm, Camilla/Lindström, Jan/Nilsson, Jenny (2019): Pragmatic variation across languages and nations: A comparative study of address patterns in medical consultations in Sweden and Finland. In: Pragmatics 29, 4, 595-621.

Wide, Camilla/Lyngfelt, Benjamin (2009): Svenskan i Finland, grammatiken och konstruktionerna ['Swedish in Finland, grammar and constructions']. In: Wide, Camilla/Lyngfelt, Benjamin (eds.): Konstruktioner i finlandssvensk syntax. Skriftspråk, samtal och dialekter ['Constructions in Finland-Swedish syntax. Written language, interaction and dialects'] (Skrifter utgivna av Svenska litteratursällskapet i Finland, 716). Helsingfors: Svenska litteratursällskapet i Finland, 11-43. 